\title{
Toll-like receptor 4 polymorphism is associated with increased susceptibility to chronic obstructive pulmonary disease in Han Chinese patients with chronic periodontitis
}

\author{
Hui Yu'1), Mei Lin'2,3), Xuejin Wang1), Songling Wang3,4), and Zuomin Wang2,3) \\ 1)Department of Stomatology, Affiliated Zhongshan Hospital of Dalian University, Dalian, P. R. China \\ 2)Department of Stomatology, Beijing Chao-Yang Hospital, Capital Medical University, Beijing, P. R. China \\ 3)Salivary Gland Disease Center and Beijing Key Laboratory of Tooth Regeneration and Function Reconstruction, \\ Capital Medical University School of Stomatology, Beijing, P. R. China \\ 4)Department of Biochemistry and Molecular Biology, Capital Medical University School of Basic Medicine, \\ Beijing, P. R. China
}

(Received March 2, 2016; Accepted June 11, 2016)

\begin{abstract}
The aim of the present study was to evaluate the association of single nucleotide polymorphisms (SNPs) in toll-like receptor 4 (TLR4) with chronic obstructive pulmonary disease (COPD) in Han Chinese patients with chronic periodontitis (CP). Six candidate SNPs of TLR4—rs10759930, rs10983755, rs11536879, rs1927907, rs11536889 and rs7873784and 18 haplotype-tagging SNPs (tagSNPs) were genotyped in 339 patients with chronic periodontitis only (CP group), and $373 \mathrm{CP}$ patients with COPD (CP with COPD group). The genotype distribution and allele frequencies of TLR4 rs1927907 among the CP (AA: 26, 8.5\%, AG: 109, 35.5\%, GG: 172, 56.0\%) and CP with COPD (AA: 41, 12.0\%, AG: 143, 41.7\%, GG: $159,46.4 \%)$ groups were significantly different $(P=0.039)$. After adjusting for age, sex, smoking status, and oral hygiene habits, CP patients carrying the AG polymorphism in TLR4 rs1927907 were found to be more susceptible to concomitant COPD than those carrying the GG genotype $(P=0.005$, OR $=1.94,95 \% \mathrm{CI}$ for $\mathrm{OR}$ : 1.22-3.03). In conclusion, TLR4 gene polymorphism plays a role in the common pathophysiology of $\mathrm{CP}$ and $\mathrm{COPD}$, indicating that $\mathrm{CP}$
\end{abstract}

Correspondence to Dr. Zuomin Wang, Department of Stomatology, Beijing Chao-Yang Hospital, Capital Medical University, 8\# Worker's Stadium South Road, Chao Yang District, Beijing 100020, P. R. China

Fax:+86-10-85231217 E-mail: wzuomin@gmail.com

doi.org/10.2334/josnusd.16-0187

DN/JST.JSTAGE/josnusd/16-0187 patients with TLR4 gene rs1927907 polymorphism may be more susceptible to COPD.

(J Oral Sci 58, 555-560, 2016)

Keywords: chronic periodontitis; chronic obstructive pulmonary disease; toll-like receptor 4; single nucleotide polymorphisms.

\section{Introduction}

Chronic periodontitis (CP) is a chronic infection caused by bacteria in dental plaque of periodontal supporting tissue, leading to periodontal pocket formation, alveolar bone resorption, attachment loss, and eventually tooth loss (1). Recently, many studies have suggested that CP not only harms periodontal tissue, but also affects wholebody health (2). It is considered a risk factor for chronic obstructive pulmonary disease (COPD), characterized by incompletely reversible limitation of airflow, recurrent cough, expectoration or accompanying wheezing (2).

Our previous study showed that $\mathrm{CP}$ is positively related to COPD (3). The severity of CP in patients with accompanying COPD was greater than that in patients without COPD. Similarly, a higher proportion of patients with severe COPD also had severe CP. Probing depth, attachment loss, plaque index, alveolar bone loss and number of lost teeth were also positively correlated with the severity of COPD (3). In addition, a low quality of life, and poor oral hygiene or health status (such as a high number of lost teeth and a high plaque index) were 
Table 1 Clinical characteristics

\begin{tabular}{|c|c|c|c|}
\hline Variables & $\mathrm{CP} n(\%)$ & $\mathrm{CP}+\mathrm{COPD} n(\%)$ & $P$ value \\
\hline \multicolumn{4}{|l|}{ Sex } \\
\hline Male & $215(63.4)$ & $293(78.6)$ & \\
\hline Female & $124(36.6)$ & $80(21.4)$ & NS \\
\hline Age & $64.04 \pm 8.30$ & $65.73 \pm 9.75$ & NS \\
\hline BMI & & & $0.001 * \mathrm{a}$ \\
\hline Normal & $99(32.5)$ & $112(36.6)$ & \\
\hline Too light & $4(1.3)$ & $20(6.5)$ & \\
\hline Overweight & $150(49.2)$ & $116(37.9)$ & \\
\hline Fat & $52(17.0)$ & $58(19.0)$ & \\
\hline Smoking history & & & $0.000^{* a}$ \\
\hline Smoking & $137(41.0)$ & $260(71.2)$ & \\
\hline Non smoking & $197(59.0)$ & $105(28.8)$ & \\
\hline Tooth brushing times & & & NS \\
\hline$>2$ time/day & $269(99.3)$ & $290(96.0)$ & \\
\hline$<2$ time/day & $2(0.7)$ & $12(4.0)$ & \\
\hline Brushing method & & & NS \\
\hline Bass brushing & $21(7.3)$ & $25(7.9)$ & \\
\hline Horizontal brush & $55(19.0)$ & $79(25.0)$ & \\
\hline Vertical brush & $112(38.8)$ & $81(25.6)$ & \\
\hline No fixed brushing & $101(34.9)$ & $131(41.5)$ & \\
\hline Oral scaling & & & NS \\
\hline$>1$ time/year & $115(35.6)$ & $65(18.2)$ & \\
\hline No & $208(64.4)$ & $292(81.8)$ & \\
\hline \multicolumn{4}{|l|}{ Periodontal parameters } \\
\hline $\mathrm{PD}$ & $3.70 \pm 1.20$ & $3.77 \pm 0.82$ & NS \\
\hline PLI & $2.80 \pm 0.50$ & $2.78 \pm 0.39$ & NS \\
\hline $\mathrm{BI}$ & $2.77 \pm 0.65$ & $2.87 \pm 1.93$ & NS \\
\hline $\mathrm{AL}$ & $6.01 \pm 1.44$ & $5.67 \pm 1.54$ & $0.003 * \mathrm{~b}$ \\
\hline $\mathrm{ABL}$ & $1.56 \pm 0.03$ & $1.48 \pm 0.02$ & NS \\
\hline
\end{tabular}

significantly related to both $\mathrm{CP}$ and $\mathrm{COPD}(4,5)$.

It has been demonstrated that the signaling molecule toll-like receptor 4 (TLR4) recognizes lipopolysaccharide (LPS) of gram negative bacteria, and further mediates innate immune or inflammatory response to pathogens in either periodontal or airway tissue (6-8). Polymorphism of TLR 4 is thought to be associated with the pathogenesis and severity of many infectious diseases such as meningococcal meningitis (9), Legionella pneumophila infection (10), and hidradenitis suppurativa (11). However, no data are yet available concerning the association of TLR 4 polymorphism with susceptibility to COPD in Han Chinese patients with CP. Therefore, the aim of the present study was to evaluate the association of single nucleotide polymorphisms (SNPs) of TLR4 with susceptibility to COPD in Han Chinese patients with CP.

\section{Materials and Methods}

\section{Patients}

Han Chinese patients with CP (CP group, $n=339)$ and with $\mathrm{CP}$ accompanied by COPD (CP+COPD group, $n=$ 373) were recruited from Beijing Chao-Yang Hospital. Inclusion criteria: 1) Han Chinese ethnicity; 2) fewer than
15 remaining teeth; 3 ) no previous periodontal treatment; 4) no pregnancy or lactation in female patients; 5) no diabetes, cardiovascular and endocrine system disorders, or other chronic diseases; 6 ) no cold, fever or other inflammatory lesions within 4 weeks of study entry. Patients were excluded if they: 1 ) were $<15$ years of age; 2 ) had experienced exacerbation of COPD symptoms (including coughing or expectoration, pyrexia, or aggravation of dyspnea); or 3) had changed medication as a result of respiratory symptoms within 4 weeks before recruitment. The clinical characteristics of the patients are shown in Table 1. This study was conducted in accordance with the Declaration of Helsinki, and the protocol was approved by the Medical Ethics Committee of Beijing Chao-Yang Hospital, Beijing, China (NO.12-27). All the participants recruited provided written informed consent to participate in this study. Written consent was obtained from all the legal guardians of any 15-18-year-old minors who were enrolled.

Examination of periodontal status and lung function In this study, periodontal status of all patients was assessed by experienced dentists. Examinations were 
Table 2 Distribution of TLR4 and alleles in CP and CP+COPD

\begin{tabular}{|c|c|c|c|c|}
\hline TLR4 & Alleles & $\mathrm{CP} n(\%)$ & $\mathrm{CP}+\mathrm{COPD} n(\%)$ & $P$ value \\
\hline \multirow[t]{5}{*}{ rs 10759930} & $\mathrm{CC}$ & $50(15.0)$ & $41(11.3)$ & \\
\hline & $\mathrm{CT}$ & $143(42.9)$ & $184(50.8)$ & 0.088 \\
\hline & TT & $140(42.0)$ & $137(37.8)$ & \\
\hline & allele $\mathrm{C}$ & $243(36.5)$ & $266(36.7)$ & 0.956 \\
\hline & allele $\mathrm{T}$ & $423(63.5)$ & $458(63.3)$ & \\
\hline \multirow[t]{5}{*}{ rs10983755 } & $\mathrm{AA}$ & $26(7.9)$ & $35(9.7)$ & \\
\hline & $\mathrm{AG}$ & $121(36.7)$ & $149(41.4)$ & 0.216 \\
\hline & GG & $183(55.5)$ & $176(48.9)$ & \\
\hline & allele A & 173 (28.9) & $219(30.4)$ & 0.094 \\
\hline & allele $\mathrm{G}$ & $487(26.2)$ & $501(69.6)$ & \\
\hline \multirow[t]{5}{*}{ rs11536879 } & $\mathrm{AA}$ & $266(73.8)$ & $292(81.1)$ & \\
\hline & $\mathrm{AG}$ & $59(17.9)$ & $59(16.4)$ & 0.591 \\
\hline & GG & $5(1.5)$ & $9(2.5)$ & \\
\hline & allele A & $591(89.5)$ & $643(89.3)$ & 0.930 \\
\hline & allele $\mathrm{G}$ & $69(10.5)$ & 77 (10.7) & \\
\hline \multirow[t]{5}{*}{ rs1927907 } & AA & $26(8.5)$ & $41(12.0)$ & \\
\hline & $\mathrm{AG}$ & $109(35.5)$ & $143(41.7)$ & $0.039 *$ \\
\hline & GG & $172(56.0)$ & $159(46.4)$ & \\
\hline & allele A & $161(26.2)$ & $225(32.8)$ & $0.011^{*}$ \\
\hline & allele $\mathrm{G}$ & $453(73.8)$ & $461(67.2)$ & \\
\hline \multirow[t]{5}{*}{ rs 11536889} & $\mathrm{CC}$ & $17(5.2)$ & $22(6.1)$ & \\
\hline & $\mathrm{CG}$ & $111(33.6)$ & $129(35.9)$ & 0.651 \\
\hline & GG & $202(61.2)$ & $208(57.9)$ & \\
\hline & allele $\mathrm{C}$ & $145(22.0)$ & $173(24.0)$ & 0.370 \\
\hline & allele $\mathrm{G}$ & $515(78.0)$ & $545(76.0)$ & \\
\hline \multirow[t]{5}{*}{ rs7873784 } & $\mathrm{CC}$ & $1(0.3)$ & $4(1.1)$ & \\
\hline & $\mathrm{CG}$ & $46(14.0)$ & $37(10.3)$ & 0.157 \\
\hline & GG & $281(85.7)$ & $319(88.6)$ & \\
\hline & allele $\mathrm{C}$ & $48(7.3)$ & $45(6.3)$ & 0.453 \\
\hline & allele $\mathrm{G}$ & $608(92.7)$ & $675(93.7)$ & \\
\hline
\end{tabular}

repeated to assess intra-examiner reliability. The kappa value of intra-examiner agreement was 0.82 . The periodontal parameters recorded on a full mouth basis included probing depth (PD), bleeding index (BI), plaque index (PLI), attachment loss (AL), and alveolar bone loss (ABL). All assessments were done at two sites per tooth in accordance with the classification of periodontitis used in the US Third National Health and Nutrition Examination Survey methods of basic oral health (12). Sites were air-dried prior to measurement and examiners used a Williams probe with an intensity of $\leq 25 \mathrm{~g}$. Periodontitis was classified as follows: 1 ) moderate periodontitis, $\geq 1$ teeth with $\geq 5 \mathrm{~mm}$ PD or $30-60 \%$ of the teeth examined having $\geq 4 \mathrm{~mm} \mathrm{PD}$; or 2) severe periodontitis, $\geq 30 \%$ of the teeth examined having $\geq 5 \mathrm{~mm}$ PD or $\geq 60 \%$ of the teeth examined having $\geq 4 \mathrm{~mm}$ PD. We selected patients with moderate and severe periodontitis and included them in our CP group (Table 1).

Spirometry was conducted according to the global initiative for chronic obstructive lung disease (GOLD) guidelines (13). The ratio of forced expiratory volume in one second (FEV1.0) to forced vital capacity (FVC) (FEV1/FVC ratio) after bronchodilator inhalation was used as the primary variable of lung function. Patients with $\mathrm{FEV} 1 / \mathrm{FVC}<0.70$ were diagnosed as having COPD.

\section{Preparation of samples and genomic DNA}

Venous blood samples $(4 \mathrm{~mL})$ were collected in disodium EDTA tubes and stored at $-20^{\circ} \mathrm{C}$. After being thawed on ice, blood samples were centrifuged for $5 \mathrm{~min}$ at 4,000 r/ $\min$. The red blood cells were discarded, and the precipitated leukocytes were resuspended in a mixture of $10 \%$ sodium dodecyl sulfonate (SDS w/v) and SE buffer (75 $\mathrm{mM} \mathrm{NaCl} ; 25 \mathrm{mM} \mathrm{Na}_{2}$ EDTA; pH 8.0) containing 100 $\mathrm{mg} / \mathrm{mL}$ protease $\mathrm{E}$ at $37^{\circ} \mathrm{C}$ overnight. After the incubation, chloroform centrifugal extraction was performed, followed by ethanol precipitation of the DNA. The DNA was washed with $70 \%$ ethanol, and then transferred to an Ependorff tube, dried, and finally stored in TE buffer $\left(200 \mu \mathrm{L}\right.$ at $\left.-80^{\circ} \mathrm{C}\right)$.

\section{Determination of TLR4 polymorphism}

SNPs of TLR4 - rs10759930, rs10983755, rs11536879, rs1927907, rs11536889 and rs7873784-were determined by real-time quantitative PCR with TaqMan MGB probe typing through 7900 HT polymerase chain 
Table 3 TLR4 (rs11536879-rs1927907-rs11536889) Haplotype analyses

\begin{tabular}{llllc}
\hline TLR4 Haplotype & CP & CP+COPD & OR & $P$ value \\
\hline AGG & 0.047 & 0.045 & & \\
AAC & 0.007 & 0.008 & $0.729[0.560-0.950]$ & $0.019^{*}$ \\
AAG & 0.214 & 0.257 & $0.807[0.614-1.061]$ & 0.125 \\
GGC & 0.212 & 0.232 & & \\
GGG & 0.456 & 0.383 & & \\
GAC & 0.009 & 0.009 & $0.700[0.435-1.128]$ & 0.143 \\
GAG & 0.055 & 0.067 & &
\end{tabular}

reaction (ABI Company, Carlsbad, CA, USA). The sequences of the primers or probes were supplied by ABI Company: rs10759930 C_2704045_20, rs 10983755 C_31783994_10,rs11536879C_31784017_10,rs1927907 C_11722137_10,rs11536889C_31784034_10,rs7873784 C_29292008_10.

The reaction conditions were $95^{\circ} \mathrm{C}$ denaturing for 10 min, $95^{\circ} \mathrm{C}$ degeneration for $15 \mathrm{~s}, 60^{\circ} \mathrm{C}$ annealing for 1 $\mathrm{min}$, for a total of 45 cycles. The genotypes were analyzed with SDS2.3 software. Results of repetitive typing and classification were entirely consistent.

\section{Statistical analysis}

Analysis was performed using the SPSS 16.0 software package (SPSS Inc., Chicago, IL, USA). The frequency distributions between genotypes and alleles were compared by $\chi^{2}$ test. The Hardy Weinberg algorithm was used to verify the equilibrium of the genotype distributions. Odds ratios (OR) and 95\% confidence intervals (CI) were determined to test the relative risk of genotypes between the $\mathrm{CP}$ and $\mathrm{CP}$ with COPD groups using the logistic regression model adjusted for sex, age, and other variables. The differences in gene ploidy were analyzed with the THESIAS software package (INSERM U525, Paris, France). Two-sided $P$ values of $<0.05$ were considered to be statistically significant.

\section{Results}

TLR4 SNPs and Hardy-Weinberg equilibrium

TLR4 genotypes were obtained from all subjects. The genotype distributions of all six SNPs were in accordance with the Hardy-Weinberg equilibrium in both groups (both $P>0.05$ ).

\section{Distribution of TLR4 and alleles}

The distribution of the TLR4 genotype is shown in Table 2. In the Han Chinese population, the GG genotype accounts for the majority of TLR4 rs1927907, which has AG or AA mutations. Significant differences in the genotype distributions $(P=0.039)$ and allele frequencies $(P=$ 0.011) of TLR4 rs1927907 were found between the CP and $\mathrm{CP}+\mathrm{COPD}$ groups. The genotype distribution and allele frequencies of other SNPs showed no significant differences $(P>0.05)$.

\section{Haplotype analysis of TLR4 rs11536879- rs1927907-rs11536889}

Seven haplotypes were constructed at the positive site of rs1927907 close to rs11536879 and rs11536889. The distribution of haplotype A-A-C (rs11536879rs1927907-rs11536889) differed significantly between the $\mathrm{CP}$ and $\mathrm{CP}+\mathrm{COPD}$ groups $(P=0.019, \mathrm{OR}=0.72$, 95\% CI for OR: 0.56-0.95) (Table 3 ).

Variables related to the prevalence of CP and COPD CP patients with the TLR4 rs1927907 SNP after adjustment for age, sex, smoking history, BMI, and oral hygiene habits showed a significantly higher prevalence of COPD than those with other SNPs. In addition, CP patients with the TLR4 rs1927907 AG genotype were twice as susceptible to COPD than those with the GG genotype $(P=0.005, \mathrm{OR}=1.94,95 \% \mathrm{CI}$ for OR: $1.22-3.03) . \mathrm{CP}$ patients who smoked (3.09 times) and did not undergo scaling (1.92 times) were more susceptible to COPD than non-smoking and scaled patients (Table 4).

\section{Discussion}

Recently, epidemiological studies have confirmed the association of periodontitis with COPD (14-17). Kowalski et al. examined the periodontal status of 100 patients with COPD, and observed a high prevalence (84.2\%) of periodontitis and a positive correlation of PD and PI with the severity of COPD (15). In addition, a high prevalence of $\mathrm{CP}$ and obvious resorption of alveolar bone were found in patients with severe COPD (15-17). Zeng performed a meta-analysis to ascertain the relationship between PD and COPD, and found that PD was a significant and independent risk factor of COPD (18). Accumulating evidence suggests that oral disorders, particularly PD, may influence the course of respiratory infections due to oral periodontopathic bacteria being aspirated into the lung, causing COPD (19). 
Table 4 Multiple factor analyses

\begin{tabular}{|c|c|c|c|c|c|}
\hline \multirow{2}{*}{ Variables } & \multirow{2}{*}{$\mathrm{B}$} & \multirow{2}{*}{$P$ value* } & \multirow{2}{*}{ OR value } & \multicolumn{2}{|c|}{$95 \% \mathrm{CI}$ of OR } \\
\hline & & & & Lower & Upper \\
\hline Age & 0.014 & 0.273 & 1.014 & 0.989 & 1.039 \\
\hline \multicolumn{6}{|l|}{ Sex } \\
\hline Female & - & - & - & - & \\
\hline Male & 0.239 & 0.422 & 1.270 & 0.709 & 2.276 \\
\hline rs1927907 & & 0.010 & & & \\
\hline GG & - & - & - & - & \\
\hline AG & 0.665 & $0.005^{\dagger}$ & 1.944 & 1.222 & 3.039 \\
\hline AA & 0.750 & 0.070 & 2.116 & 0.940 & 4.764 \\
\hline BMI & & 0.001 & & & \\
\hline Normal & - & - & - & - & \\
\hline Too light & 1.107 & 0.104 & 3.025 & 0.769 & 11.489 \\
\hline Overweight & -0.848 & $0.001^{\ddagger}$ & 0.428 & 0.262 & 0.701 \\
\hline Fat & -0.378 & 0.265 & 0.685 & 0.353 & 1.332 \\
\hline \multicolumn{6}{|l|}{ Smoking status } \\
\hline Non smoking & - & - & - & - & \\
\hline Smoking & 1.131 & $0.001^{\ddagger}$ & 3.098 & 1.816 & 5.285 \\
\hline \multicolumn{6}{|l|}{ Tooth brushing times } \\
\hline$>2$ time/day & - & - & - & - & \\
\hline$<2$ time/day & 0.985 & 0.291 & 2.679 & 0.429 & 16.715 \\
\hline Brushing method & & 0.528 & & & \\
\hline Bass brushing method & - & - & - & - & \\
\hline Horizontal brush method & 0.024 & 0.955 & 1.024 & 0.447 & 2.384 \\
\hline Vertical brush method & -0.375 & 0.353 & 0.687 & 0.312 & 1.515 \\
\hline No fixed brushing method & -0.273 & 0.508 & 0.761 & 0.339 & 1.709 \\
\hline \multicolumn{6}{|l|}{ Supra-gingival scaling } \\
\hline$>1$ time/year & - & - & - & - & \\
\hline No & 0.654 & $0.009^{\dagger}$ & 1.924 & 1.177 & 3.145 \\
\hline
\end{tabular}

In the present study, we also found a positive correlation between CP and COPD. The frequency and distribution of TLR4 rs 1927907 alleles were significantly different between the $\mathrm{CP}$ and $\mathrm{CP}+\mathrm{COPD}$ groups. In the Han Chinese population, the GG genotype accounts for the majority of the distribution of TLR4 rs 1927907, which has AG or AA mutations. It has been suggested that $\mathrm{CP}$ patients with TLR4 gene rs1927907 polymorphism (SNP: AG) may be more susceptible to COPD. However, the distribution of TLR4 A-A-C (rs11536879-rs1927907-rs11536889) haplotypes also showed a significant difference between the $\mathrm{CP}$ and $\mathrm{CP}+\mathrm{COPD}$ groups, suggesting a negative contribution of these haplotypes to susceptibility to periodontitis combined with COPD.

TLRs, as important immune receptors, act as a bridge between innate and acquired immunity (6). TLRs recognize highly conserved molecular patterns (i.e. pathogen-associated molecular patterns, PAMPs) in specific microorganisms such as lipopolysaccharide (LPS) in gram negative bacteria (6). A combination of TLR4 with LPS induces the production of inflammatory cytokines such as IL-1, IL- 6 and TNF- $\alpha$, and mediates innate immune and inflammatory response, resulting in destruction of periodontal tissue (20-22). On the other hand, LPS has been shown to increase TLR4 mRNA in airway epithelia isolated from COPD patients (23). MacRedmond et al. have also found that the severity of COPD was closely associated with expression of TLR4 in the respiratory epithelia (8). The minor $\mathrm{C}$ allele of the rs11536889 TLR4 gene SNP is likely associated with the risk of developing emphysema in Japanese subjects with COPD (24). Also the TLR4 rs11536889 C allele was previously demonstrated to be associated with moderate and severe periodontitis (25). The TLR4 rs4986790 SNP significantly interacts with $P$. gingivalis in conferring a decreased risk of periodontitis and may be protective against ABHL, a feature of periodontitis (26). Therefore, based on the results of TLR4 genotyping mentioned above, and the fact that TLR4 contributes to the pathogenesis of CP and COPD, TLR4 gene polymorphism may partly explain the susceptibility of CP patients to COPD. Furthermore, CP patients who smoked (3.09 times) and did not undergo scaling (1.92 times) were more susceptible to COPD than non-smoking and scaled patients.

In conclusion, TLR4 gene polymorphism plays a role in the common pathophysiology of CP and COPD, indicating that CP patients with TLR4 gene rs1927907 polymorphism may be more susceptible to COPD. 


\section{Acknowledgments}

This study was supported by the National Nature Science Foundation of China (30872878 and 81271158). The authors would like to thank the clinical staff of the Department of Respiratory Medicine, Beijing Chao-Yang Hospital, affiliated to Capital Medical University, for their kind assistance.

\section{Conflict of interest}

The authors have no conflicts of interest to declare.

\section{References}

1. Brown LJ, Löe H (1993) Prevalence, extent, severity and progression of periodontal disease. Periodontol 2000 2, 57-71.

2 Scannapieco FA, Ho AW (2001) Potential associations between chronic respiratory disease and periodontal disease: analysis of National Health and Nutrition Examination Survey III. J Periodontol 72, 50-56.

3. Wang Z, Zhou X, Zhang J, Zhang L, Song Y, Hu FB et al. (2009) Periodontal health, oral health behaviours, and chronic obstructive pulmonary disease. J Clin Periodontol 36, 750-755.

4. Zhou X, Wang Z, Song Y, Zhang J, Wang C (2011) Periodontal health and quality of life in patients with chronic obstructive pulmonary disease. Respir Med 105, 67-73.

5. Liu Z, Zhang W, Zhang J, Zhou X, Zhang L, Song Y et al. (2012) Oral hygiene, periodontal health and chronic obstructive pulmonary disease exacerbations. J Clin Periodontol 39, 45-52.

6. Yoshimura A, Kaneko T, Kato Y, Golenbock DT, Hara Y (2002) Lipopolysaccharides from periodontopathic bacteria Porphyromonas gingivalis and Capnocytophaga ochracea are antagonists for human toll-like receptor 4. Infect Immun 70, 218-225.

7. Ratner AJ, Lysenko ES, Paul MN, Weiser JN (2005) Synergistic proinflammatory responses induced by polymicrobial colonization of epithelial surfaces. Proc Natl Acad Sci U S A 102, 3429-3434.

8. MacRedmond RE, Greene CM, Dorscheid DR, McElvaney NG, O'Neill SJ (2007) Epithelial expression of TLR4 is modulated in COPD and by steroids, salmeterol and cigarette smoke. Respir Res 8, 84.

9. van Well GT, Sanders MS, Ouburg S, Kumar V, van Furth AM, Morré SA (2013) Single nucleotide polymorphisms in pathogen recognition receptor genes are associated with susceptibility to meningococcal meningitis in a pediatric cohort. PLoS One 8, e64252.

10. Zhang F, Gao XD, Wu WW, Gao Y, Zhang YW, Wang SP (2013) Polymorphisms in toll-like receptors 2, 4 and 5 are associated with Legionella pneumophila infection. Infection 41, 941-948.

11. Savva A, Kanni T, Damoraki G, Kotsaki A, Giatrakou S, Grech I et al. (2013) Impact of Toll-like receptor-4 and tumour necrosis factor gene polymorphisms in patients with hidradenitis suppurativa. Br J Dermatol 168, 311-317.
12. Albandar JM, Brunelle JA, Kingman A (1999) Destructive periodontal disease in adults 30 years of age and older in the United States, 1988-1994. J Periodontol 70, 13-29.

13. Vestbo J, Hurd SS, Agustí AG, Jones PW, Vogelmeier C, Anzueto A et al. (2013) Global strategy for the diagnosis, management, and prevention of chronic obstructive pulmonary disease: GOLD executive summary. Am J Respir Crit Care Med 187, 347-365.

14. Hayes C, Sparrow D, Cohen M, Vokonas PS, Garcia RI (1998) The association between alveolar bone loss and pulmonary function: the VA Dental Longitudinal Study. Ann Periodontol 3, 257-261.

15. Kowalski M, Kowalska E, Split M, Split W, WierzbickaFerszt A, Pawlicki L et al. (2005) Assessment of periodontal state in patients with chronic obstructive pulmonary disease-part II. Pol Merkur Lekarski 19, 537-541.

16. Leuckfeld I, Obregon-Whittle MV, Lund MB, Geiran O, Bjørtuft $\varnothing$, Olsen I (2008) Severe chronic obstructive pulmonary disease: association with marginal bone loss in periodontitis. Respir Med 102, 488-494.

17. Deo V, Bhongade ML, Ansari S, Chavan RS (2010) Periodontitis as a potential risk factor for chronic obstructive pulmonary disease: a retrospective study. Indian J Dent Res 20, 466-470.

18. Zeng XT, Tu ML, Liu DY, Zheng D, Zhang J, Leng W (2012) Periodontal disease and risk of chronic obstructive pulmonary disease: a meta-analysis of observational studies. PLoS One 7, e46508.

19. Bansal M, Khatri M, Taneja V (2013) Potential role of periodontal infection in respiratory diseases--a review. J Med Life 6, 244-248.

20. Medzhitov R, Preston-Hurlburt P, Janeway CA Jr (1997) A human homologue of the Drosophila Toll protein signals activation of adaptive immunity. Nature 388, 394-397.

21. Barton GM, Medzhitov R (2003) Toll-like receptor signaling pathways. Science 300, 1524-1525.

22. Beklen A, Sorsa T, Konttinen YT (2009) Toll-like receptors 2 and 5 in human gingival epithelial cells co-operate with T-cell cytokine interleukin-17. Oral Microbiol Immunol 24, 38-42.

23. Pace E, Giarratano A, Ferraro M, Bruno A, Siena L, Mangione $S$ et al. (2011) TLR4 upregulation underpins airway neutrophilia in smokers with chronic obstructive pulmonary disease and acute respiratory failure. Hum Immunol 72, 54-62.

24. Ito M, Hanaoka M, Droma $Y$, Kobayashi N, Yasuo M, Kitaguchi Y et al. (2012) The association of Toll-like receptor 4 gene polymorphisms with the development of emphysema in Japanese subjects: a case control study. BMC Res Notes 5, 36.

25. Fukusaki T, Ohara N, Hara Y, Yoshimura A, Yoshiura K (2007) Evidence for association between a Toll-like receptor 4 gene polymorphism and moderate/severe periodontitis in the Japanese population. J Periodontal Res 42, 541-545.

26. Sellers RM, Payne JB, Yu F, LeVan TD, Walker C, Mikuls TR (2016) TLR4 Asp299Gly polymorphism may be protective against chronic periodontitis. J Periodontal Res 51, 203-211. 